\title{
The Neorectum Reservoirs
}

Wong M.P.K. ${ }^{a}$, Abdel Latif K Elnaim ${ }^{a}$, Sagap $I^{a}$

${ }^{a}$ Colorectal Unit, Department of Surgery, Universiti Kebangsaan Malaysia Medical Centre, Kuala Lumpur, Malaysia

\section{ABSTRACT}

The incidence of rectal dissection is increasing with the rise of rectal cancer all over the world. This technique has been used regularly to provide a reasonable quality of life for patients. The concern raised was the functions of these neorectum to replace the original rectum. Several configurations have been suggested namely the straight end-to-end coloanal anastomosis, side-to-end coloanal anastomosis, colonic Jpouch and the transverse coloplasty to suit the anatomy of the deep pelvis. Apparently, there was no difference in terms of functional outcome among all these four types of reconstructions. However, these configurations have seen the emergence of anterior resection syndrome or a pragmatic defaecatory dysfunction as their complications. Furthermore, the neorectum functions are affected by many other factors such as preoperative chemoradiotherapy, septic complications, and others more.

KEYWORDS: Neorectum, Anterior Resection, Anterior Resection Syndrome, Bowel Dysfunction, Defaecatory Dysfunction

\section{INTRODUCTION}

\section{The principles of Neorectum}

Neorectum is anatomical colonic reconstruction performed as a replacement of the resected rectum. These new reservoirs are meant to emulate the function of the rectum. There is still limited understanding with regards to the restoration of the physiological function of the rectum. Many efforts have been made to investigate the functional quality of life of those who have a rectal resection. The rectum acts as a reservoir of stool before defaecation. Its characteristic include adaptive compliance to the difference in the pressure gradient; continuous tonic contraction of the puborectalis that creates the acute angulation and the tonic contractions of the internal anal sphincter to maintain the continence. ${ }^{1}$ As the rectum gets distended, the rectoanal inhibitory reflex is activated causing relaxation of the internal sphincter. The contraction of pelvic muscles and external anal sphincter will maintain the continence

Corresponding Author:

Assoc. Prof. Datuk Dr. Ismail Sagap

Colorectal Unit,

Department of Surgery,

Universiti Kebangsaan Malaysia Medial Centre,

Kuala Lumpur, Malaysia.

Tel No: +603- 9145 6201/6202

Email: drisagap@yahoo.com when defaecation is not convenient. In the final stage of defaecation, stool expulsion is propagated by the squatting position which straightens the anorectal angle, Valsalva manoeuvre, inhibitory signal to relax the pelvic muscle and the external anal sphincter. ${ }^{2}$

Based on the Malaysia Cancer Registry Report 2016, colorectal cancer is the most common cancer in male and second most common cancer in the female, and when combined it is the second most common cancer affecting our population. ${ }^{3}$ Our data reported the leftsided and rectal tumour stands for 71.1 per cent of all colorectal cancer presented to our centre. ${ }^{4}$ From the GLOBOCAN project, it was reported that Malaysia has the third highest colorectal cancer in South East Asia. $^{5}$

Other reasons for rectal resection are restorative panproctocolectomy for patients with ulcerative colitis, familial adenomatous polyposis, juvenile polyposis syndrome and enbloc rectal resection with gynaecological malignancy such as ovarian or uterine cancer.

Several issues have raised concern in neorectum reconstruction. Among others are the pre-operative radiotherapy, re-do rectal surgery, and narrowed 
male pelvis which are thought to affect the physiological function of the reconstruction significantly. In their systematic review, Westerduin et al. ${ }^{6}$ found 79 per cent successful redo anastomosis with only five studies reported failure in the form of incontinence.

\section{Functional Alteration of Neorectum and Anterior}

\section{Resection Syndrome}

Anterior resection syndrome (ARS) is a defaecatory dysfunction which occur after rectal resection. The symptoms may vary from urgency, frequency, stool clustering, flatus incontinence to constipation. They are debilitating result in the deteriorating quality of life. The pathophysiology of anterior resection syndrome is poorly understood. Bryant et al. ${ }^{7}$ suggested several interesting pathophysiologies of ARS pointing towards anal sphincter damage, preoperative radiotherapy, an anastomotic technique with neorectal configuration, colonic and neorectal motility function.

The anal sphincter was postulated to be inadvertently injured via two mechanisms; the internal anal sphincter injury during the endoanal instrumentation for anastomosis and the intramural nerve plexus injury during the pelvic dissection to achieve a good oncological total mesorectal excision. ${ }^{8,9}$ On the other hand, the neorectal configurations in terms of reservoir volume created and the direction of anastomosis was postulated to influence the defaecatory function by the reservoir compliance. ${ }^{7}$ Studies have reported that the motility variation of the proximal colon has earlier and more frequent peristalsis contraction compared to the hindgut. ${ }^{10,11}$ Hence, the configuration of the neorectum is important to overcome this as it may lead to symptoms of frequency, urgency and stool clustering which is a pragmatic description of ARS or defaecatory dysfunction.

Meanwhile, the effect of radiotherapy on the neorectum was thought to cause neorectal hyposensitivity leading to the occurrence of the anterior resection syndrome. ${ }^{12}$ It was noted that the resting anal sphincter pressure is significantly lowered after radiotherapy. One suggested theory was the alteration of hot and cold temperature by radiotherapy causing hypersensitive neorectum, lower resting anal sphincter pressure and reduced neorectal compliance leading defaecatory urgency. ${ }^{12,13}$

Recent sphincter-sparing surgery such as intersphincteric resection, robotic or laparoscopic rectal resection and transanal total mesorectal excision of rectal tumour enable us to better preserve the pelvic autonomic nerves without compromising the oncological resection. However, the functional outcome was loosely explored. Anorectal manometry studies have also shown that despite sphincter-preserving surgery, the maximum resting anal pressure and maximum squeeze pressure were also significantly lowered leading to defaecatory dysfunction during the early postoperative period but the rectoanal inhibitory reflex recovered over 12 months. ${ }^{14,15}$ This might interpret into better functional capacity to the patient with these techniques.

Anterior resection syndrome (ARS) peaked at three months post-operative period and declined after 12 months. This coincides with the period of bowel adaptation of 6 months to 2 years. This is made worse in those patients with pre-operative radiotherapy and a total mesorectal excision. ${ }^{16}$

\section{The LARS Score}

The LARS score was developed from a large Danish cohort comprises of 961 patients. The item selections and scores are based on the prevalence and the impact on quality of life (QoL). The five items selected were incontinence for flatus, incontinence for liquid stool, increased frequency (number of daily bowel movements), clustering (the need to re-evacuate within an hour of the last bowel movement), and urgency.

The questionnaires gather information about the frequency of the episode of the symptoms and it does not use a specifically recall period. The original Danish version was validated to many other languages and the English version was validated in 2015 with a high convergent and discriminative validity and reliability in corelating LARS to quality of life. ${ }^{17}$ All the items in the questionnaire were adjusted to individual scores and the total scores was used to grade the LARS severity as No LARS, Minor LARS and Major LARS. ${ }^{18}$ 


\section{Neorectum Configurations \& Its Functional Value}

Over the past decades, efforts are being done to review the configuration of these neorectum and their significance in restoring the function of the rectum. There is a lot of interest recently due to the emergence of anterior resection syndrome which could be related to increasing number of sphincter-sparing surgery for rectal tumour resection - intersphincteric resection (ISR), transanal total mesorectal excision of the rectal tumour, and ultra-low anterior resection.

The common neorectum configurations are the straight end-to-end or side-to-end anastomosis, Jpouch and Transverse coloplasty. ${ }^{19}$ The straight endto-end anastomosis is most straightforward to construct with the introduction of a circular stapler. This technique was perceived to cause defaecatory dysfunction. Hence, many modified colonic reservoirs were recommended.

The J-Pouches are introduced as the surgeon observed the increased in defaecatory dysfunction after rectal surgery. ${ }^{20}$ There are two types of J-Pouches-the colonic and ileal J-pouches. Ileal $\mathrm{J}$-pouch used in restorative panproctocolectomy for inflammatory bowel disease is $15 \mathrm{~cm}$ stapled anastomosis pouch ${ }^{21}$ while colonic J-pouch used in rectal cancer surgery is smaller 4 to $5 \mathrm{~cm}$ pouches. ${ }^{22,23}$ The dilemma lies with the inconsistency of the reservoir volume created. If the reservoir is overtly big especially in colonic J-pouch, it will cause incomplete evacuation hence, leading to prolong requirement of laxatives, enema, rectal irrigation and in severe cases digital manual evacuation. ${ }^{24}$ If the reservoir is too small as initially constructed with either end-to-end or side-to-end anastomosis, the new reservoir has higher colonic motility due to a proximal colonic construct, hence, producing incontinence, clustering of stool, urgency and frequency. ${ }^{7,10,11}$ Both extremes of the neorectum construct brings to ARS and disrupt the quality of life. Function wise, it was found that Jpouches performed better than other configurations up to 2 years after which they began to deteriorate with time. ${ }^{25}$

The transverse coloplasty pouch was introduced by Z'graggen et al. ${ }^{26}$ They advocated the simplicity of the procedure with the standard end-to-end anastomosis by performing an incision $2 \mathrm{~cm}$ above the anvil, creating a longitudinal incision about 7 $9 \mathrm{~cm}$ in length. Then, this incision was sutured in an anti-anatomical direction like performing a pyloroplasty. The procedure aims to interrupt the peristalsis wave when the longitudinal muscle and intrinsic nervous plexus is cut during colotomy. ${ }^{24}$ With this, it provides a tension-free end-to-end anastomosis and at the same time creates a small size reservoir as the neorectum. The advantage of this is the usage among the obese patients with thick and short mesocolon and narrow pelvis. The functional outcome was comparable to the colonic $\mathrm{J}$ pouch. ${ }^{27}$

This technique has been modified by Grimaldi et al. who created a smaller pouch using a linear stapler. ${ }^{24}$ Almost like the original transverse coloplasty pouch, the incision begins $3 \mathrm{~cm}$ above the anvil, with the length of incision only $5 \mathrm{~cm}$ and the coloplasty is performed with the aid of a linear stapler. ${ }^{24}$ From their cohort, they were able to demonstrate with the smaller reservoir and the resolution of ARS was improved to 2 months, thus improved quality of life.

In recent years, several studies have compared all reconstruction performances. Fazio and co-workers reported no significant difference in functional outcome and quality of life after 24 months among all different neorectum reconstruction. ${ }^{28}$ Consequently, in a meta-analysis by Heriot et al. ${ }^{29}$ comparing the straight colo-anal anastomosis, colonic J-pouch and coloplasty concluded that the colonic J-pouch produces better functional benefits compared to the straight coloanal anastomosis in terms of lesser faecal urgency. They also found that there is no functional outcome difference between the colonic J-pouch and coloplasty.

More recently, Hüttner et al. ${ }^{19}$ had seen that colonic $\mathrm{J}$-pouch has a better functional outcome in the first one year compared to the straight end-toend anastomosis. However, with regards to their functional and leak complications, it was noted that there is no difference between the side-to-end anastomosis and transverse coloplasty when compared to the colonic J-pouch. ${ }^{19}$

\section{CONCLUSION}

In conclusion, all the four types of neorectal configurations have their own merits. Up to date, we 
learned that the better functional outcomes are seen with the colonic J-pouch over 24 months, but the functions did not progress henceforth. In other words, any configurations of neorectum reconstruction would yield similar functional outcome in the long run.

\section{CONFLICT OF INTERESTS}

All the authors declare no financial conflict of interests upon the preparation of this manuscript.

\section{ACKNOWLEDGEMENT}

We wish to thank the department of surgery, Universiti Kebangsaan Malaysia Medical Centre for providing discussion room and printing facilities to ensure the completion of this writing.

\section{REFERENCES}

1. Barleben, A. \& Mills, S. Anorectal Anatomy and Physiology. Surg. Clin. North Am. 90, 1-15 (2010).

2. Palit, S., Lunniss, P. J. \& Scott, S. M. The physiology of human defecation. Dig. Dis. Sci. 57, 1445-1464 (2012).

3. Ab Manan, A., Ibrahim Tamin, N. S., Abdullah, N. H., Zainal Abidin, A. \& Wahab, M. Malaysian National Cancer Registry Report 2007-2011 Malaysia Cancer Statistics, Data And Figure. National Cancer Institute (2016).

4. Samem, Z. M. A. et al. A Review of Relationship Between Presenting Symptoms and Tumour Location in Colorectal Carcinoma in Tertiary Centre Hospital. Malaysian J. Public Hel 18, 2834 (2018).

5. Abu Hassan, M. R. et al. Incidence and mortality rates of colorectal cancer in Malaysia.

Epidemiol. Health 38, e2016007 (2016).

6. Westerduin, E. et al. Outcome After Redo Surgery for Complicated Colorectal and Coloanal Anastomosis: A Systematic Review. Dis. Colon Rectum 61, 988-998 (2018).

7. Bryant, C. L. C., Lunniss, P. J., Knowles, C. H., Thaha, M. A. \& Chan, C. L. H. Anterior resection syndrome. Lancet Oncol. 13, e403-e408 (2012).

8. Ho, Y. H. et al. Anal sphincter injuries from stapling instruments introduced transanally: Randomized, controlled study with endoanal ultrasound and anorectal manometry. Dis. Colon Rectum 43, 169-173 (2000).
9. Farouk, R., Duthie, G. S., Lee, P. W. R. \& Monson, J. R. T. Endosonographic evidence of injury to the internal anal sphincter after low anterior resection: Long-term follow-up. Dis. Colon Rectum 41, 888-891 (1998).

10. Mochiki, E. et al. Barostat examination of proximal site of the anastomosis in patients with rectal cancer after low anterior resection. World J. Surg. 25, 1377-1382 (2001).

11. Willis, S., Hölzl, F., Wein, B., Tittel, A. \& Schumpelick, V. Defecation mechanisms after anterior resection with J-pouch-anal and side-to -end anastomosis in dogs. Int. J. Colorectal Dis. 22, 161-165 (2007).

12. Bregendahl, S. et al. Neorectal hyposensitivity after neoadjuvant therapy for rectal cancer. Radiother. Oncol. 108, 331-336 (2013).

13. Innát, P. et al. Anorectal dysfunction after laparoscopic low anterior rectal resection for rectal cancer with and without radiotherapy (manometry study). J. Surg. Oncol. 117, 710716 (2018).

14. Pedersen, I. K. et al. Anorectal Function after Low Anterior Resection for Carcinoma. Ann. Surg. 133-135 (1986).

15. Kitaguchi, D., Nishizawa, Y., Sasaki, T., Tsukada, Y. \& Ito, M. Clinical benefit of high resolution anorectal manometry for the evaluation of anal function after intersphincteric resection. Color. Dis. codi.14528 (2018). doi:10.1111/codi.14528

16. Emmertsen, K. J. \& Laurberg, S. Impact of bowel dysfunction on quality of life after sphincter-preserving resection for rectal cancer. Br. J. Surg. 100, 1377-1387 (2013).

17. Juul, T. et al. International validation of the low anterior resection syndrome score. Ann. Surg. 259, 728-734 (2014).

18. Emmertsen, K. J. \& Laurberg, S. Low anterior resection syndrome score: Development and validation of a symptom-based scoring system for bowel dysfunction after low anterior resection for rectal cancer. Ann. Surg. 255, 922 -928 (2012).

19. Hüttner, F. J. et al. Meta-analysis of reconstruction techniques after low anterior resection for rectal cancer. British Journal of Surgery 102, 735-745 (2015).

20. Brown, S. et al. Morbidity following coloanal anastomosis: A comparison of colonic $\mathrm{j}$-pouch vs straight anastomosis. Dis. Colon Rectum 61, 156 -161 (2018). 
21. Carne, P. \& Pemberton, J. Technical Aspects of lleoanal Pouch Surgery. Clin. Colon Rectal Surg. 17, 35-41 (2004).

22. Parc, R., Tiret, E., Frileux, P., Moszkowski, E. \& Loygue, J. Resection and colo-anal anastomosis with colonic reservoir for rectal carcinoma. Br. J. Surg. 73, 139-141 (1986).

23. Lazorthes, F., Fages, P., Chiotasso, P., Lemozy, J. \& Bloom, E. Resection of the rectum with construction of a colonic reservoir and coloanal anastomosis for carcinoma of the rectum. Br. J. Surg. 73, 136-138 (1986).

24. Grimaldi, G. et al. Modified transverse coloplasty pouch: new reconstruction techniques after total mesorectal excision. Our experience. G. Chir. 38, 285-290 (2017).

25. Barrier, A. et al. Long-term functional results of colonic $J$ pouch versus straight coloanal anastomosis. Br. J. Surg. 86, 1176-1179 (1999).

26. Z'graggen, K., Maurer, C. A. \& Büchler, M. W. Transverse Coloplasty Pouch. Dig. Surg. 16, 363 -366 (1999).

27. Ulrich, A., Z\&apos;graggen, K., SchmitzWinnenthal, H., Weitz, J. \& Büchler, M. W. The transverse coloplasty pouch. Langenbeck's Arch. Surg. 390, 355-360 (2005).

28. Fazio, V. W. et al. A Randomized Multicenter Trial to Compare Long-Term Functional Outcome, Quality of Life, and Complications of Surgical Procedures for Low Rectal Cancers. (2007). doi:10.1097/SLA.0b013e3181485617

29. Heriot, A. G. et al. Meta-analysis of colonic reservoirsversus straight coloanal anastomosis after anterior resection. Br. J. Surg. 93, 19-32 (2006). 